\title{
Ultrasonication for Environmentally Friendly Preparation of Antimicrobial and Catalytically Active Nanocomposites of Cellulosic Textiles
}

\author{
Joanna Kwiczak-Yiǧitbaşı," Mine Demir," Recep Erdem Ahan, Sedat Canlı, Urartu Özgür Şafak Şeker, \\ and Bilge Baytekin*
}

Cite This: ACS Sustainable Chem. Eng. 2020, 8, 18879-18888

Read Online

ABSTRACT: The global demand for sustainable and functional fibers and textile materials is increasing with the pressure to limit the synthetic petroleum-based counterparts. In this study, we use ultrasonication for the preparation of eco-friendly cellulose fabrics bearing silver or gold nanoparticles (NPs). The mechanochemistry of cellulose is based on the breakage of glycosidic bonds and the formation of mechanoradicals. These mechanoradicals can reduce $\mathrm{Au}^{3+}$ and $\mathrm{Ag}^{+}$ions in solution, and the reduced metals can be stabilized by the cellulose chains as nanoparticles. Here, we formed the mechanoradicals in the fabrics by sonication (on the order of $10^{18}$ per gram), which is confirmed by ESR. The sizes and the metallic nature of NPs and the structural and morphological changes in the fabrics upon

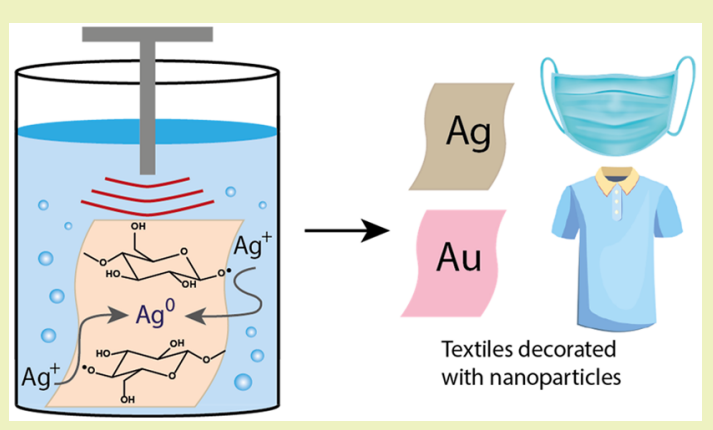
ultrasonication were studied by SEM, XPS, FTIR-ATR, XRD, and TEM. The displayed preparation method is shown to yield antibacterial AgNP-fabric and catalytically active AuNP-fabric composites, with up to a $14 \%$ yield of metal ion reduction. Since the method involves only the sonication of the fabric in aqueous solutions, and uses no hazardous reducing and stabilizing agents, it provides quick and environment-friendly access to fabric nanocomposites, which have applications in medical textiles, catalysis, and materials for energy.

KEYWORDS: sonication, mechanochemistry, sonochemistry, antimicrobial fabrics, cellulose nanocomposites

\section{INTRODUCTION}

Global environmental plastic pollution is one of the major threats to life on Earth. The rate of pollution is only increasing by the accelerated use of synthetic nondegradable polymers, which cannot be sustainably recycled. Substituting many of these materials with sustainable products and natural fibers can be a way to lift the weight from the environment. Therefore, noteworthy attention is devoted to cellulose materials and cellulose-based composites. The fabrics made from cellulose find applications in many areas including textiles and construction materials. Especially the former has gained more importance in the recent pandemic, as homemade reusable face masks are mostly made of cellulose fabrics. Cellulose fabrics have superior properties owing to cellulose's inherent properties, such as biodegradability, mechanical strength, and durability. ${ }^{1,2}$ With the incorporation of (nano)materials into polymers, nanocomposites can be formed, which can be useful in catalysis, ${ }^{3}$ medicine, ${ }^{4}$ or industrial applications. $^{5}$ The catalytically active nanocomposites are mostly employed in wastewater management, for the degradation of organic pollutants generated from agricultural and industrial sources. Gold nanocomposites of cellulose, too, were successfully used as such catalytic components. ${ }^{6-9}$ Silver nanocomposites of cellulose fabrics and cellulose, on the other hand, display antimicrobial action. ${ }^{10-20}$ The preparation of such functional nanocomposites usually requires multistep procedures and employs the usage of toxic reagents and solvents-especially for the reduction of the metal ions into their metallic form and for the stabilization of the metals as nanoparticles. ${ }^{13-15}$ Recently, some environment-friendly synthetic approaches were reported for the preparation of nanoparticles not only on the cellulose matrix ${ }^{21-24}$ but also on other biopolymers. ${ }^{25-29}$ However, the addition of other chemical components such as bases $\left(\mathrm{NaOH}, \mathrm{Na}_{2} \mathrm{CO}_{3}\right), \mathrm{H}_{2} \mathrm{O}_{2}$, or acids are still required in these approaches. A more inclusive solution for the above-mentioned disadvantages of the conventional nanocomposite preparation can be eliminated by employing mechanochemistry, which has provided many straightforward and green alternatives to conventional

Received: July 27, 2020

Revised: October 10, 2020

Published: December 11, 2020 
syntheses of biocompatible and multifunctional materials. . $^{9}, 30-35$

Mechanochemistry is based on the breakage of chemical bonds by the application of mechanical input such as ball milling. For common synthetic polymers and biopolymers, homolytic cleavage of the polymer backbones leads to the formation of mechanoradicals as reported in numerous studies. $^{9,36-39}$ These mechanoradicals can be used to stabilize static charges on polymer surfaces, in dye bleaching, and in nanoparticles formation. ${ }^{9,38,40}$ The mechanical treatment of cellulose, i.e. in a ball mill, causes mechanochemical cleavages of glycosidic bonds, which leads to the formation of cellulose mechanoradicals. Sakaguchi et al. characterized these radicals by Electron Spin Resonance Spectroscopy (ESR) as alkyl (carbon-centered), alkoxyl (oxygen-centered), and peroxy (when the milling was performed in air) radicals. ${ }^{41}$ In several studies, these mechanoradicals were used as an initiator in the polymerization of monomers such as styrene, methyl methacrylate, and hydroxyethyl methacrylate, for the preparation of cellulose-synthetic polymer copolymers. ${ }^{37,42,43}$ Using the cellulose mechanoradicals generated through the cryomilling (ball milling under cryo conditions) of cotton, we previously prepared metal nanocomposites of silver, gold, platinum, and palladium straightforwardly by adding only the corresponding metal ion solutions to cryomilled cotton. Since this method involves the reduction of metals with the formed mechanoradicals and the stabilization of NPs within the cellulose chains, it eliminates not only the multistep processes but also the utilization of hazardous reducing or stabilizing agents. ${ }^{9}$

A disadvantage of ball milling is, however, its poor applicability to large-scale production. Therefore, when mass production is needed, such as for fabrics, sonication stands as a more practical method. Gold, silver, gold/palladium, and zinc oxide nanoparticles have been reported to form by the sonochemical method. ${ }^{44-51}$ In nanocomposite preparation, the sonochemical method offers controllable reaction conditions, shorter reaction times, cleaner processes (often following green chemistry rules), and also high purities and uniform shapes of the formed nanoparticles. ${ }^{52}$

In this study, we report the first-time preparation of cotton and cotton fabric/Au and $\mathrm{Ag}$ nanoparticle composites via sonication (Figure 1). Our method is green, simple, and onepot: We sonicate cotton or fabric to cause scission of cellulose chains and generate cellulose mechanoradicals, which reduce the aqueous metal ions to the metal nanoparticles. The formed nanoparticles are stabilized by the chains of the cellulose matrix. This way, we bypass the further steps of conventional nanocomposite preparation, which involves the use of hazardous reducing and stabilizing agents, the use of organic solvents, and purification. As the matrix, we use the ecofriendly cotton fabric, and fabrics made from natural sourcesviscose and Tencel (two examples of regenerated cellulose), because these fabrics are widely used in the textile industry. The cotton- and fabric-based $\mathrm{Au}$ and $\mathrm{Ag}$ nanocomposites prepared act as catalysts in the reduction of 4-nitrophenol. We also test the antimicrobial action of the prepared cotton fabric-, viscose-, and Tencel-Ag nanocomposites against E. coli (Gramnegative bacteria) and B. subtilis (Gram-positive bacteria). The formation of the radicals during the sonication of cellulose is confirmed by ESR studies, and the radicals are quantified using the well-known "2,2-diphenyl-1-picrylhydrazyl (DPPH) radical scavenging" method. ${ }^{53-55}$ The morphological and structural

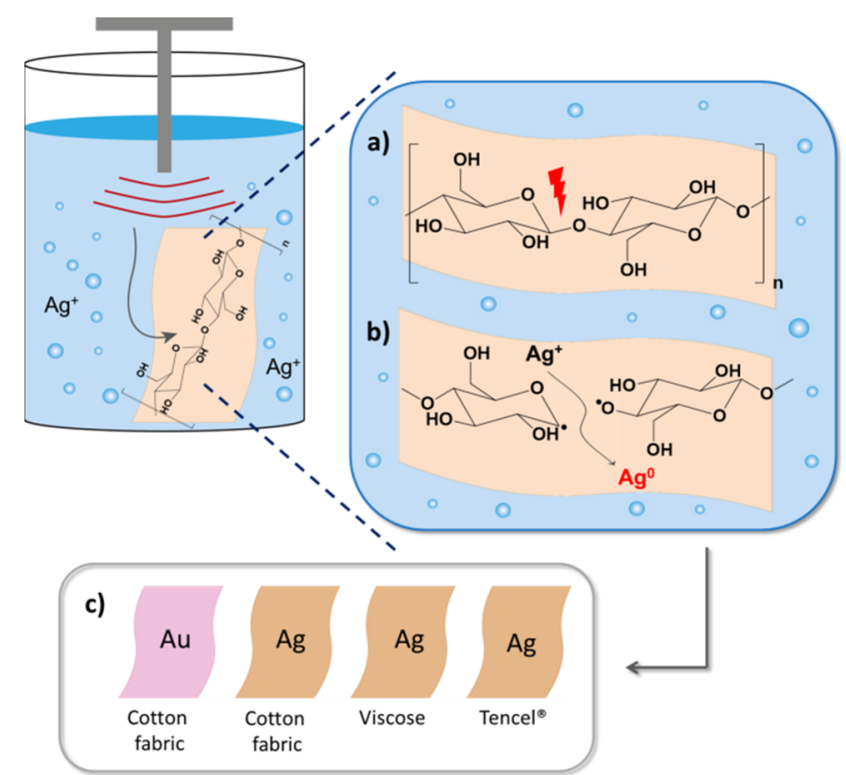

Figure 1. Preparation of the fabric-metal nanocomposites through ultrasonication. (a) The acoustic energy of the ultrasound is transformed into chemical energy, which is absorbed by fabrics leading to the 1,4-glycosidic bond scissions and the formation of mechanoradicals. (b) Mechanoradicals reduce the metal ions present in the solution $\left(\mathrm{HAuCl}_{4}, \mathrm{AgNO}_{3}\right.$ in $\left.\mathrm{H}_{2} \mathrm{O}, 6 \mathrm{~mL}, 2.5 \mathrm{mM}\right)$ to metal nanoparticles resulting in (c) the formation of cotton fabric-, viscose-, and Tencel-metal nanocomposites.

changes in the cellulose during the sonochemical treatment are monitored with FTIR-ATR, SEM, and XRD. We show that the bond breakages in the amorphous domains of cellulose caused by sonication produce enough radicals to lead to the formation of metal nanoparticles on the surfaces of cotton and cotton fabric samples, without a significant change in the crystallinity and the fibrillar structure of cellulose. ${ }^{55}$

\section{RESULTS AND DISCUSSION}

The Formation of Cellulose Mechanoradicals. When cellulose is exposed to mechanical treatment, free radicals are formed by the 1,4-glycosidic bond scission. The primarily generated radicals (alkyl and alkoxyl) are extremely reactive and can be involved in various chemical transformations (Figure S1). ${ }^{41,56,57}$ For example, alkoxy radicals may participate in $\beta$-fragmentation forming more stable carbonyl species, ${ }^{36}$ and $\mathrm{C}$-centered radicals can react with oxygen present in the atmosphere followed by the formation of more stable peroxy radicals. ${ }^{41,57}$ In this study, we observed the formation of these radicals upon sonication of four cellulosic samples: cotton, cotton fabric, viscose, and Tencel. The samples were sonicated for $30 \mathrm{~min}$ in acetonitrile at room temperature, and ESR spectra of the ultrasonicated samples were recorded immediately after the treatment. Since ESR measurements were performed under ambient conditions, we expect to have mostly secondarily formed peroxy radicals with a characteristic ESR signal ( $g$ value of 2.006).$^{57}$ In addition to this, we also expect a contribution of coforming alkoxy radicals, giving rise to a "mixed" signal of alkoxy and peroxy cellulose radicals in the ESR spectra. In this case, we observed this signal ( $g$ value of 2.003) in the spectra of the sonicated samples (Figures 2a, S2). The cellulosic radicals decayed in air, a couple of minutes after sonication. 


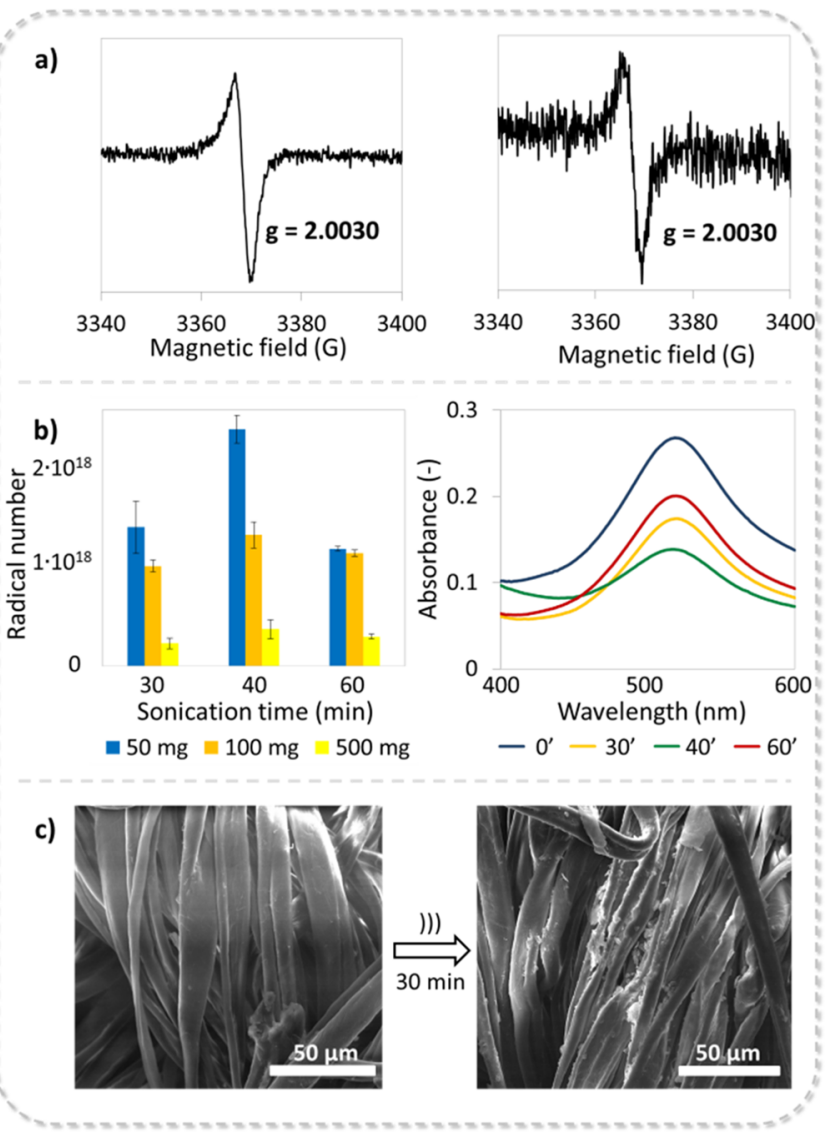

Figure 2. (a) ESR spectra of cotton (left) and cotton fabric (right). The samples were sonicated for $30 \mathrm{~min}$ in acetonitrile at room temperature, followed by the immediate ESR measurements. The spectra confirm the formation of radicals with $g$ values equal to 2.0030. (b) The number of mechanoradicals per gram of cotton formed by the sonication of different cotton quantities $(50,100,500$ $\mathrm{mg}$ ) at indicated times (30, 40, $60 \mathrm{~min}$; left) and UV-vis spectra of DPPH solutions in acetonitrile, in which the sonicated cotton samples were immersed for indicated times $(0,30,40,60 \mathrm{~min}$; right). (c) SEM images of the cotton fabric before (left) and after $30 \mathrm{~min}$ of sonication (right). Images show that the fibers are slightly damaged upon sonication; however, the bulk form of the fabric is preserved.

As we have previously reported, ${ }^{55}$ cellulose radicals can be quantified using a well-known radical scavenger DPPH by tracing the decrease in the UV-vis absorption of the DPPH solution at its maximum (519 nm; Figure $2 \mathrm{~b})$. Before the experiments, all samples (cotton, cotton fabric, viscose, Tencel) were washed with ethanol and dried to remove any radicals that could have formed during the sample handling. Then, the DPPH solution was added to the sonicated cellulose (sonication times: 30 to $60 \mathrm{~min}$ ). The sample was left to stay in the DPPH solution for $6 \mathrm{~h}$, by which time the radicals that were generated in the bulk migrated to the surface of the cellulose and reacted with DPPH (Figure S3). ${ }^{38}$ (Increasing the waiting time of the cellulose sample in the DPPH solution more than $6 \mathrm{~h}$ did not increase the number of radicals significantly (Figure S3).) Approximately $10^{17}$ up to $10^{18}$ radicals per gram of cellulose were formed during the sonication of cotton (Figure $2 \mathrm{~b}$, Table S1). The number of radicals increased while the sonication time was changed from 30 to $40 \mathrm{~min}$. However, increasing the sonication time to 60 min did not lead to a higher number of radicals, presumably because of the concurrent radical recombination. The other parameter, which impacts the production of mechanoradicals is the amount of the sample used during the sonication (Figure $2 b$ ). Table $S 1$ shows that up to 6 times more radicals can be produced when a smaller amount of cotton is sonicated. The numbers of radicals generated in cotton fabric, viscose, and Tencel (sonicating $50 \mathrm{mg}$ of the sample during $30 \mathrm{~min}$ ) were determined to be $1.22 \times 10^{18}, 1.60 \times 10^{18}$, and $1.54 \times 10^{18}$, respectively (Table $\mathrm{S} 1$ ). Here, we also note that nonsonicated samples, also left to stay in the DPPH solutions under the same conditions as the sonicated ones, did not lead to any change in the UV-vis absorption spectrum of the DPPH solutions, proving that the radicals formed only during sonication.

Morphological and Structural Changes of the Sonicated Cotton and Fabrics. After sonicating cotton and fabrics, samples were washed and dried to investigate any morphological and structural changes by SEM, XRD, and FTIR-ATR. SEM images of cotton and fabric samples (Figures $2 c, 54-S 9$ ) indicate that the fibers were only slightly damaged upon the sonication process. These changes were more pronounced when the sonication time increased and also when lower amounts of the samples were subjected to a mechanical process-sonicating $50 \mathrm{mg}$ of cotton caused more fiber damage than sonicating $100 \mathrm{mg}$ or $500 \mathrm{mg}$ of sample since the mechanical energy is transferred more efficiently to the lower amounts of sample (also reflected in the higher radical number formed upon sonication of lower amounts (Table S1)). The damages that occurred on the fibers, however, did not lead to their disintegration (Figures 2c, S4S9), so the fiber morphology did not change dramatically (Stefanovic et al. also pointed out that the molecular weight $\left(M_{\mathrm{w}}\right)$ of cotton upon $120 \mathrm{~min}$ of sonication drops only to $80 \%$ of the initial $M_{\mathrm{w}}^{58}$ ). The overall morphology preservation is a good indication that the fabrics treated ultrasonically can further be used in making textile goods, just like the untreated fabrics.

XRD diffractograms of cotton and cotton fabric before sonication show diffraction lines at approximately $2 \theta: 15.29^{\circ}$, $16.82^{\circ}, 23.33^{\circ}$, and $34.88^{\circ}$, which corresponds to crystallographic planes of $(1 \overline{1} 0),(110),(200)$, and (400), respectively, and cellulose I crystalline structure (Figure S10). ${ }^{59}$ Regenerated cellulose fibers like viscose and Tencel have a cellulose II crystalline structure, which was confirmed by the presence of diffraction lines at approximately $2 \theta: 12.61^{\circ}, 20.38^{\circ}$, and $21.96^{\circ}$ for nonsonicated viscose and $12.51^{\circ}, 20.70^{\circ}$, and $21.85^{\circ}$ for nonsonicated Tencel (Figure S11). These lines correspond to crystallographic planes of $(1 \overline{1} 0),(110)$, and (200), respectively. ${ }^{60,61}$ As presented in the XRD diffractograms of cotton and fabrics (Figure S10 and S11), no significant change in crystallinity occurred after sonication of the samples for indicated times (Table S2, see SI for details of the crystallinity index calculations). Thus, sonication does not disintegrate crystalline domains of cotton and fabrics, which shows that the mechanical energy is absorbed mostly by the amorphous parts of the cellulose samples, and this is where the major bond scission and formation of mechanoradicals take place. (Previously, we showed similar results upon milling of cotton and microcrystalline cellulose under cryo conditions in the presence of a solvent. ${ }^{55}$ ) FTIR-ATR spectra of the sonicated cotton samples revealed characteristic bands present in cellulose such as $\mathrm{O}-\mathrm{H}$ stretching at $3100-3500 \mathrm{~cm}^{-1}$, glycosidic stretching at $1100 \mathrm{~cm}^{-1},-\mathrm{CH}-$ rocking at 992 $\mathrm{cm}^{-1}$, and $\mathrm{C}-\mathrm{O}$ ring stretching at $980 \mathrm{~cm}^{-1}$ (Figures $\mathrm{S} 12-$ $\mathrm{S} 15){ }^{62,63} \mathrm{~A}$ very slight increase in the band at $1620 \mathrm{~cm}^{-1}$, 

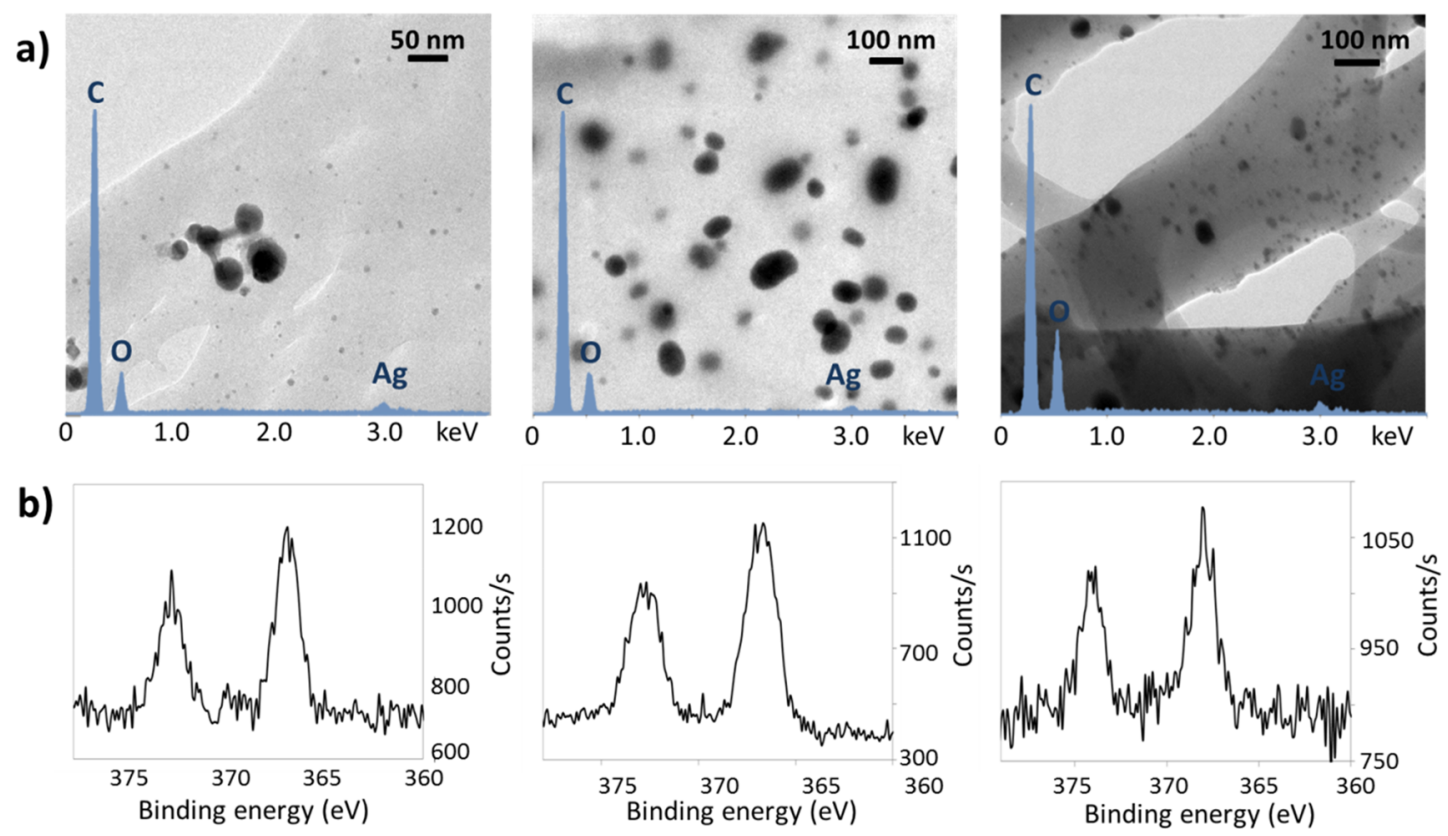

Figure 3. (a) The EDX spectra (shown in blue) and TEM images of cotton fabric-Ag (left), viscose-Ag (middle), and Tencel-Ag (right) nanocomposites prepared by the sonication of the cotton or fabric sample in an aqueous solution of metal ion precursor $\left(\mathrm{AgNO}_{3}, 6 \mathrm{~mL}, 2.5 \mathrm{mM}\right)$. Sonication time $=30 \mathrm{~min}$. (b) HIRES XPS spectra of the cotton fabric-Ag (left), the viscose-Ag (middle), and the Tencel-Ag (right) nanocomposites verifying the metallic nature of the formed NPs.

which is assigned to $\mathrm{C}=\mathrm{O}$ stretching, indicates that during sonication cotton is slightly oxidized (Figures S12-S14). However, no major structural changes were observed upon sonication up to $60 \mathrm{~min}$ of different cotton amounts as well as fabrics (Figures S16, S17).

Preparation and Characterization of Cotton-Au, Cotton Fabric-Au, Cotton Fabric-, Viscose-, and Tencel-Ag Nanocomposites. In a typical preparation, cotton or fabric samples were sonicated in a metal ion precursor solution $\left(\mathrm{HAuCl}_{4}\right.$ or $\mathrm{AgNO}_{3}$ in $\mathrm{H}_{2} \mathrm{O}, 6 \mathrm{~mL}, 2.5$ $\mathrm{mM})$. To optimize the deposition of nanoparticles on the samples, different sonication times were used in the cotton-Au nanocomposite preparation. A fine deposition of $\mathrm{Au}$ NPs on the cotton matrix was achieved after 30 and $40 \mathrm{~min}$ of sonication (sonicating for lower times did not cause appreciable NPs formation; Figure S18). The atomic percentage of gold (atom \%) calculated based on XPS spectra indicated that the atom $\%$ of $\mathrm{Au}$ NPs is equal to $0.043 \%$, and $0.042 \%$ after 30 and $40 \mathrm{~min}$ of sonication, respectively. Therefore, $30 \mathrm{~min}$ was chosen as the duration of sonication. SEM and TEM images of the nanocomposites showed the metal NPs as spots in the cellulose matrix; 15-30 nm (cotton$\mathrm{Au}$ ), 20-30 nm (cotton fabric-Au), 5-40 nm (cotton fabric$\mathrm{Ag}$ ), 20-100 nm (viscose-Ag), and 3-40 nm (Tencel-Ag) in size (Figures 3a, S18-S20). The SEM images also verified that the NPs did not aggregate into larger particles, even after weeks of sample storage. Hence, we conclude that due to the weak secondary bonding of NPs and hydroxyl and the ether group of cellulose, the nanoparticles are well stabilized in the cellulose matrix. ${ }^{64}$ EDX spectra (Figures $3 a$ and S21) displayed signals at $2.13 \mathrm{eV}$ and $3.00 \mathrm{eV}$, indicating the presence of $\mathrm{Au}$ and $\mathrm{Ag}$ atoms, respectively. The absence of the accompanying elements' signals in the EDX spectra revealed that the samples are free from the metal ion precursors. High-resolution X-ray photoelectron spectroscopy (HIRES XPS) of the prepared cotton and fabric nanocomposites confirmed the successful reduction of metal ions to metal NPs by the presence of the metallic forms of $\mathrm{Au}(0)$ and $\mathrm{Ag}(0)$ only (Figure 3b, S22). The reflectance spectra also verified the presence of $\mathrm{Ag}$ and $\mathrm{Au}$ nanoparticles on the fabric matrices by displaying the characteristic surface plasmon resonance corresponding to $\mathrm{Ag}$ and Au NPs, respectively (Figure S23). ${ }^{65,66}$ Additionally, X-ray diffraction (XRD) analysis of the nanocomposites containing Au NPs showed the diffraction peaks at $2 \theta: 38.3^{\circ}, 45.6^{\circ}, 65.8^{\circ}$, and $77.6^{\circ}$, corresponding to the crystallographic planes of (111), (200), (220), and (311), respectively, confirming the face-centered cubic structure of $\mathrm{Au}(0)$ (Figure S24). The color of the fabrics changed from white to purple (of the Au NPs) and brown (of the Ag NPs) upon the formation of the corresponding nanocomposites, as supported by RGB analyses (Figure S25). The overall yield of the gold ion reduction based on the ICP-MS measurements was found to be $6 \%$ and $3 \%$ for cotton- and cotton fabric-Au nanocomposites, respectively (Table S3). The yield of silver ion reduction was equal to $14 \%$, $10 \%$, and $12 \%$ for cotton fabric-, viscose-, and Tencel-Ag nanocomposites, respectively. We note that, since aqueous metal ion solutions are used in the experiments, metal ions are reduced either directly by mechanoradicals or by secondary products of these mechanoradicals such as the hydroxyl radicals that are generated when these radicals react with water (Figure S26). 9,38,67,68 We also emphasize that choosing lower sonication power $(70 \mathrm{~W}$ instead of $150 \mathrm{~W}$ ) decreased the yield of the metal nanoparticle deposition, and no deposition of NPs was observed (SEM and XPS) on the cotton or fabric samples left to stay in the metal ion solution for $30 \mathrm{~min}$.

Mechanical tests of fabrics demonstrated a slight difference in Young's moduli in the warp direction in comparison to the weft direction. ${ }^{69}$ However, Young's modulus $(E)$ did not change after the sonication and the formation of nanoparticles (Figure S27). For example, $E$ in the warp direction is equal to $2.3 \pm 0.5 \mathrm{MPa}$ and $1.8 \pm 0.7 \mathrm{MPa}$ for the cotton fabric and cotton fabric-Ag nanocomposite, respectively. This lack of 
change in the mechanical properties might be attributed to two opposite effects: the softening of the fabric because of the damages caused by the sonication process (Figures 2c, S4-S9) and the stiffening of the fabric because of the incorporation of metals after the formation of the composite. ${ }^{70,71}$

The Catalytic Action of Cotton-Au and Cotton FabricAu Nanocomposites. Since cellulose-based nanocomposites were successfully used as catalysts in the reduction of 4nitrophenol (4-NPh) to 4-aminophenol (4-APh) with $\mathrm{NaBH}_{4}{ }^{6-9}$ we decided to test this activity with cotton- and fabric-based nanocomposites prepared via sonication, where the transformation was monitored by UV-vis spectrophotometry. After $\mathrm{NaBH}_{4}\left(0.375 \mathrm{~mL}, 0.70 \mathrm{M}\right.$ in $\left.\mathrm{H}_{2} \mathrm{O}\right)$ was introduced into a solution of 4-NPh $\left(3 \mathrm{~mL}, 0.30 \mathrm{mM}\right.$ in $\left.\mathrm{H}_{2} \mathrm{O}\right)$, the mixture turned yellow due to the deprotonation of 4-NPh reflected by a band with a maximum at $400 \mathrm{~nm}$ in the UV-vis spectrum (Figures 4 and S28). It is important to point out that

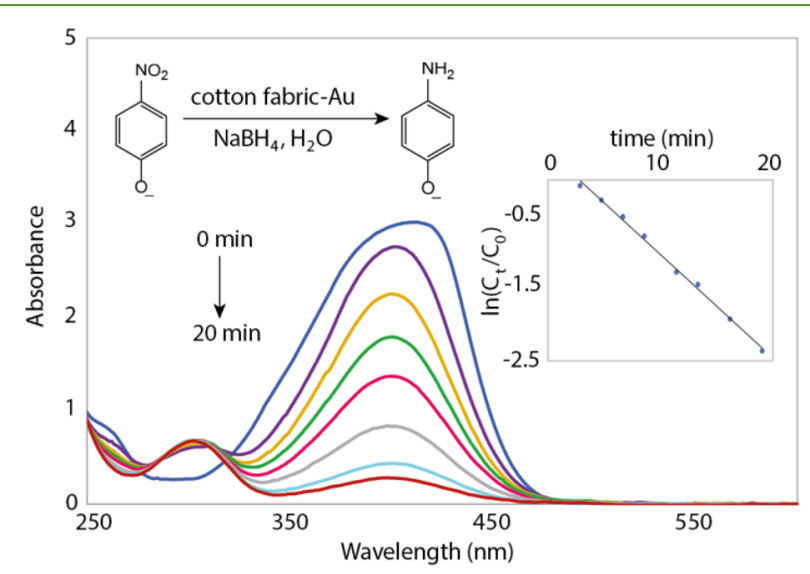

Figure 4. 4-NPh reduction catalyzed by the cotton fabric-Au nanocomposite followed by UV-vis spectroscopy. The reaction follows first-order kinetics as shown by the linear $\ln \left(C_{t} / C_{0}\right)$ vs time plot (inset).

no catalytic activity was observed without the presence of the fabric catalyst. However, when the cotton-Au, fabric-Au, or fabric-Ag nanocomposite (metal content in $10 \mathrm{mg}$ of composite: $33 \mu \mathrm{g}, 16 \mu \mathrm{g}, 46 \mu \mathrm{g}, 32 \mu \mathrm{g}$, and $38 \mu \mathrm{g}$, in cotton- $\mathrm{Au}$, cotton fabric-Au, cotton fabric-Ag, viscose-Ag, and tencel-Ag nanocomposite, respectively, Table S3) was added to the reaction mixture, the characteristic absorbance band at 400 $\mathrm{nm}$ decreased, and a new band corresponding to 4-APh with a maximum at $300 \mathrm{~nm}$ emerged (Figures 4, S28). Depending on the used catalyst, the reduction was completed between 14 and $30 \mathrm{~min}$. The kinetic parameters such as the rate constant $k$, half time $t_{1 / 2}$, and correlation coefficient were calculated for 0 , first, and second order reaction models, and the results are presented in Table S4. The best correlation, as also indicated by the linear plot $\ln \left(C_{t} / C_{0}\right)$ vs time $\left(C_{t}\right.$ and $C_{0}$ represent the concentration of 4-NPh at $400 \mathrm{~nm}$ at designated time $t$ and $t=$ 0, respectively; Figures 4, S28), was achieved for the first-order reaction model, which fits the data reported by others. ${ }^{6-9}$ The highest rate constant was found to be $0.173 \pm 0.009 \mathrm{~min}^{-1}$ for viscose-Ag nanocomposite, while the lowest $k$ was found for the cotton-Au nanocomposite: $0.074 \pm 0.001 \mathrm{~min}^{-1}$ (Table S4). Thus, the catalytic performance of the fabric-based nanocomposites was superior to the cotton-Au nanocomposite. This difference can be attributed to better access of $\mathrm{NaBH}_{4}$ to nanoparticles deposited on the flat surface of fabric-based nanocomposites, rather than to nanoparticles coated on the cotton fibers, which penetrate each other. ${ }^{72}$ Catalysts prepared in this study displayed better catalytic activity than $\mathrm{Au}$ or $\mathrm{Ag}$ nanoparticles supported on carboxymethyl methylcellulose, cellulose nanocrystals, or dextran ${ }^{8,26,73,74}$ but slightly lower than those deposited on microcrystalline cellulose, crystalline cellulose nanofibers, or polymer-coated cellulose nanocrystals. ${ }^{6,7,9,75}$ Nevertheless, this comparison is only demonstrative, because the catalysis of 4-nitrophenol transformation depends on many factors such as size and shape of NPs, or a polymeric matrix, and herein-since the present study aims for a proofof-concept-we refrain from making further optimizations for maximization of the efficiency. After the reduction of 4-NPh, composites were recovered, washed, dried, and recycled in the next catalysis (Figure S29). The constant rate of the second catalytic cycle dropped in case of the usage of all nanocomposites as presented in Table S4. Even though NPs remain in their metallic form after first and second catalysis as shown by the XPS measurement (Figure S30), ICP-MS measurements revealed that the content of gold in $10 \mathrm{mg}$ of nanocomposite decreased from $33.4 \mu \mathrm{g}$ to $8.8 \mu \mathrm{g}$ for cotton$\mathrm{Au}$ and from $16.0 \mu \mathrm{g}$ to $5.5 \mu \mathrm{g}$ for cotton fabric-Au. This might be caused by the leakage of NPs to the solution caused by the swelling and conformational changes of cellulose during the absorption of water by the matrix.

The Antimicrobial Action of Cotton Fabric-, Viscose-, and Tencel-Ag Nanocomposites. Antimicrobial fabrics have a broad range of applications including wound dressing materials, daily clothes, and textures designed for healthcare facilities. ${ }^{76-78}$ Inhibition of bacteria growth on fabrics can decrease the spread of multi-drug-resistant harmful pathogens such as MRSA. $^{79}$ Also, the formation of unpleasant odor molecules, which are the metabolic byproduct of bacterial growth, can be prevented. $^{80}$ In previous applications, antimicrobial AgNP nanocomposite fabric materials were successfully obtained by reactive dyeing ${ }^{81}$ or in situ synthesis with citrate medium. ${ }^{82}$ Therefore, we prepared composites of Ag nanoparticles with common fabrics such as cotton, viscose, and Tencel via ultrasonication. Ag nanoparticles were chosen as antimicrobial agents because of maximum potency against bacterial cells and minimum side toxicity on human health. ${ }^{83}$ The effect of the Ag NPs incorporation in fabrics via sonication on bacterial growth was tested with Gram-positive (B. subtilis) and Gram-negative (E. coli) bacteria strains via standard agar disk diffusion. In a typical experiment, UV-sterilized and circleshaped fabrics were placed in the middle of an agar plate and were incubated at $37{ }^{\circ} \mathrm{C}$ overnight. Control fabrics were nontoxic to both bacteria strains (growth free zones were not observed in fabrics that were not carrying $\mathrm{Ag} \mathrm{NPs}$ ). Meanwhile, Ag NPs loaded on the fabrics inhibited the growth of $E$. coli and B. subtilis around them, yet they were more potent against E. coli in comparison to B. subtilis (Figure 5a,b). Ag NPs coated on cotton and viscose had similar antimicrobial activity on both bacteria strains compared to each other. The highest activity on both of the bacteria strains was exhibited by the Tencel-Ag nanocomposite (Figure 5c). Even though the concentration of Ag NPs was not the highest for the Tencel-Ag nanocomposite (Table S3), its leading antimicrobial activity can be explained by the formation of the smallest in size $\mathrm{Ag}$ NPs on Tencel $(3-40 \mathrm{~nm})$ in comparison to viscose (Ag NPs $20-100 \mathrm{~nm}$ ) and cotton fabric (Ag NPs 5-40 nm; Figures 3a, S20). These results are supported by others, which indicated that the reduced size of Ag NPs is a fundamental parameter for 
a)
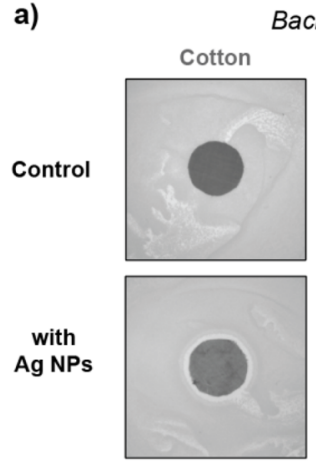

Bacillus subtilis (Gram +)

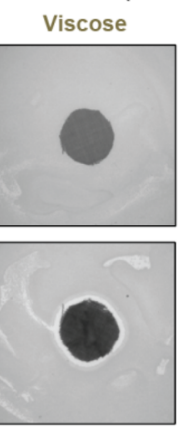

b)
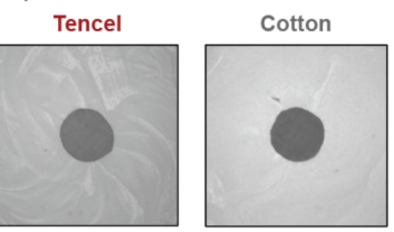

Escherichia coli (Gram -)
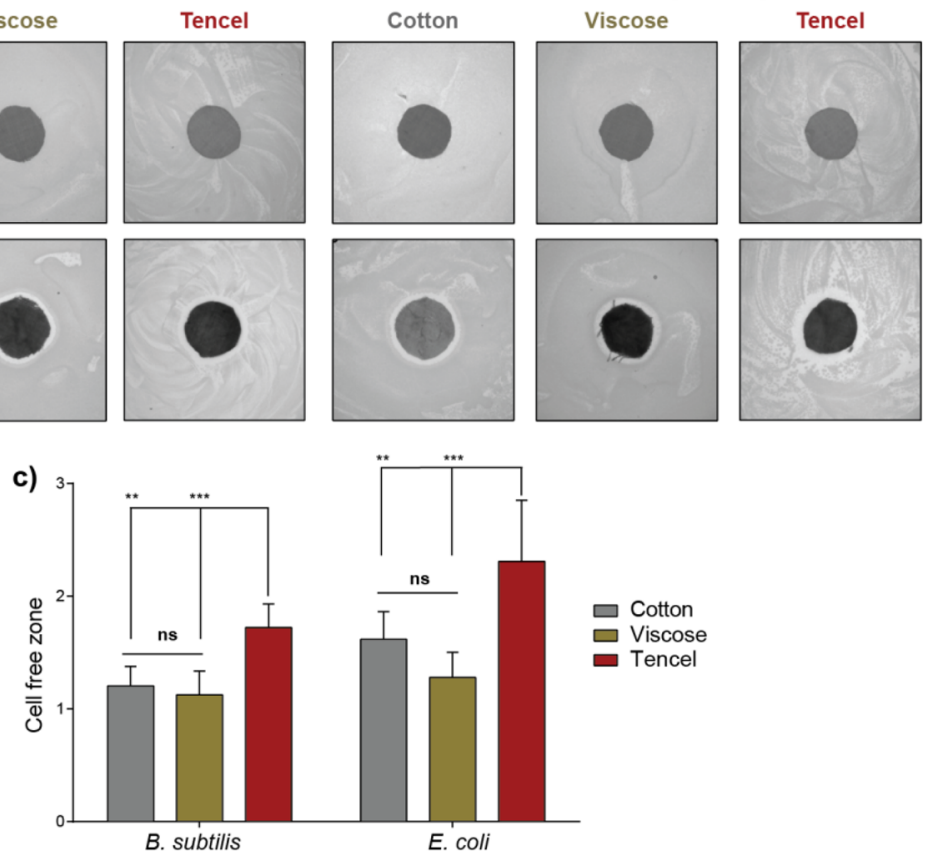

Figure 5. Antimicrobial activity of Ag nanoparticles coated on cotton fabric, viscose, and Tencel. (a) Area of inhibition of fabrics on agar growing Bacillus subtilis. (b) Area of inhibition of fabrics on agar growing Escherichia coli. (c) Comparison of the cell-free zone of fabrics in mm. Experiments were performed in triplicate. To calculate the cell-free zone in each plate, distance from fabrics to smear zone was measured for at least eight points, and the average of measured distances was taken. Two-ANOVA was used to assess statistical significance $(* * P<0.01, * * * P<0.001)$.

displaying better antimicrobial activity. ${ }^{84}$ Another important factor for fabric-Ag nanocomposites is their washing durability. In this work, prepared fabrics were washed through a certain number of laundering cycles $(5,10$, and 15 times) in an aqueous solution of commercially available detergent. ${ }^{85}$ Nevertheless, ICP-MS measurement indicated, that most of the Ag NPs are washed off the fabrics after the cycles, and the samples did not show antimicrobial activity anymore. To overcome this problem and prevent Ag NPs from leaking, we decided to coat a representative example of the fabric samples with the highest antimicrobial action, Tencel-Ag nanocomposites, with sustainable biopolymers such as alginate and agarose. These types of environmentally friendly coatings have already been successfully used in the development of antimicrobial textiles. ${ }^{85-88}$ Thus, after the formation of a thin layer of agarose or alginate gel on the fabric surface, the washing process was performed. The presence of metallic silver in the coated and washed samples was confirmed by HIRES XPS (Figure S31). Also, based on the XPS survey spectra, the atomic percentage of $\mathrm{Ag} \mathrm{NPs}$ in the coated samples was calculated and presented in Table S5. The influence of coating and washing on the antimicrobial action was also investigated in the same manner as described above (agar disk assay). Control samples, agarose- and alginate-coated Tencel not bearing Ag NPs, displayed no toxicity to both bacteria strains (Figure S32). On the contrary, even if the coated samples containing Ag NPs were washed many times, they still largely preserved the antimicrobial activity before coating (Figures 5, S32). Also, antibacterial action did not depend on the coating type and did not change with an increasing number of laundering cycles, which indicates that both agarose and alginate prevent Ag NPs from leaking. Greater standard deviations obtained for some coated samples may be explained by a couple of factors. First, during each sonication process, there can be a deviation in the number of coated Ag NPs, which influenced final antimicrobial activity. Moreover, the wettability of the samples in the agar disk was challenging; consequently, the release of the silver ions could be distorted from sample to sample. Nevertheless, we proved that coating fabrics bearing nanoparticles with biopolymers is a promising and environmentally friendly solution for keeping the antimicrobial properties during increased washing cycles.

\section{EXPERIMENTAL SECTION}

Materials. As a cellulose matrix, the following samples were used: commercially available cotton (obtained from local pharmacy), fabric cotton $\left(\right.$ Co., weight $\left.=120 \mathrm{~g} / \mathrm{m}^{2}\right)$, viscose $\left(\right.$ Co., weight $\left.=120 \mathrm{~g} / \mathrm{m}^{2}\right)$, and tencel $\left(\right.$ Co., weight $\left.=120 \mathrm{~g} / \mathrm{m}^{2}\right)$. 4-Nitrophenol from Acros Organics was used. Hydrogen tetrachloroaurate(III) trihydrate and silver nitrate were purchased from ABCR. 2,2-Diphenyl-1-picrylhydrazyl, acetonitrile, and sodium borohydride were purchased from Sigma-Aldrich. Gold and silver plasma emission standards were purchased from VWR. For antimicrobial activity experiments, the $E$. coli K-12 MG1655 strain and B. subtilis 168 strain were used. Sodium chloride, tryptone, yeast extract, and agar powder for growth media preparation were purchased from Sigma-Aldrich.

Instrumentation. Ultrasonic Processor. In all experiments, sonication of cellulose samples was performed with a HilscherUP200 St Powerful Ultrasonic Lab Homogenizer equipped with a titanium sonotrode (diameter equal to $7 \mathrm{~mm}$ ).

Electron Spin Resonance Spectroscopy (ESR). ESR spectra were recorded on Bruker ELEXSYS E580 model ESR spectrometer equipped with a high-sensitivity cavity and operating at X-band frequencies $(9 \mathrm{GHz})$. Measurements were performed under nonsaturating conditions. The following experimental conditions were used: $0.3 \mathrm{~mW}$ microwave power, $0.25 \mathrm{mT}$ modulation amplitude, 41 ms conversion time, $41 \mathrm{~ms}$ time constant, and 1024 points.

Scanning Electron Microscopy (SEM) and Energy Dispersive $X$ ray (EDX) Analyses. The surface morphology of cellulose samples and fabric-metal NPs was imaged and analyzed with a Quanta 200F model 
SEM with an accelerating voltage of $15 \mathrm{kV}$. Samples not bearing NPs were coated with Au-Pd (thickness $0.1 \mathrm{k} \AA$ ).

Transmission Electron Microscopy (TEM). The fabric-metal NP nanocomposites were imaged with FEI Tecnai F30 Twin $300 \mathrm{kV}$ model.

Focused Ion Beam-Scanning Electron Microscopy (FIB-SEM). The surface morphology of the tencel-Ag nanocomposite was imaged and analyzed with FEI Nova NanoLab 600i with an accelerating voltage of $2 \mathrm{kV}$.

$X$-ray Photoelectron Spectroscopy (XPS). XPS spectra were recorded on ESCALAB 250 (Thermo Scientific K-Alpha X-ray Photoelectron Spectrometer). Photoemission was stimulated by monochromatic $\mathrm{Al} \mathrm{K}$ alpha radiation $(1486.6 \mathrm{eV})$. Survey scans and high-resolution scans were collected using pass energies of 200 and 30 $\mathrm{eV}$, respectively. Binding energies in the spectra were referenced to the $\mathrm{C} 1 \mathrm{~s}$ binding energy set at $284.8 \mathrm{eV}$. At least three different measurements were performed for each sample.

$X$-ray Diffraction (XRD). XRD spectra were recorded on an X'Pert PRO PANalytical model X-ray diffractometer with $\mathrm{Cu} \mathrm{K} \alpha$ radiation. A $40 \mathrm{~mA}$ current and a $45 \mathrm{kV}$ accelerating voltage were used.

UV-Vis Spectroscopy. The absorption spectra were recorded using a Cary 100 Bio UV-visible spectrophotometer from Varian.

UV-Vis Diffuse Reflectance Spectroscopy. The reflectance spectra were recorded using a Cary 5000 UV-vis-NIR spectrophotometer from Varian. Labsphere SRS-99-010 was used as a reflectance standard in the wavelength range of $250-800 \mathrm{~nm}$.

Fourier Transform Infrared Attenuated Total Reflectance (FTIRATR). FTIR-ATR spectra were obtained in the range of 4000-400 $\mathrm{cm}^{-1}$ with a Bruker Alpha model spectrometer with Platinum ATR crystal.

Stress-Strain Testing. Stress-strain tests were conducted on an Instron 5969 Universal Testing System with a $100 \mathrm{~N}$ load cell and a rate of $50 \mathrm{~mm} / \mathrm{min}$. The samples were prepared according to the JIS K6251-8 standard.

Inductively Coupled Plasma Mass Spectrometry (ICP-MS). For the determination of gold content in cotton- and cotton fabric-Au nanocomposites: ICP-MS was recorded on PerkinElmer Nexion 350D equipped with a Cyclonic Spray Chamber and Glass Meinhard Concentric Nebulizer. The system operated with a nebulizer gas flow of $0.92 \mathrm{~L} \cdot \mathrm{min}^{-1}$, plasma gas flow rate of $18 \mathrm{~L} \cdot \mathrm{min}^{-1}$, auxiliary gas flow rate of $1.2 \mathrm{~L} \cdot \mathrm{min}^{-1}$, and ignition power of $1300 \mathrm{~W}$. Samples were dissolved in aqua regia. For the determination of silver content in cotton fabric-, viscose-, and tencel-Ag nanocomposites: ICP-MS was recorded on Thermo Fischer Scientific XSeries 2 ICP-MS equipped with Peltiercooled Spray Chamber, a high-performance glass concentric nebulizer, and a standard quartz torch. The system was operated in peak jumping mode, at a dwell time of $10000 \mathrm{~ms}$, a nebulizer gas flow of $0.8 \mathrm{~L} \cdot \mathrm{min}^{-1}$, sweeps per reading of 100 , and ignition power of 880 $\mathrm{W}$. The samples were dissolved in concentrated $\mathrm{HNO}_{3}$.

ESR Studies on the Radical Formation. A total of $50 \mathrm{mg}$ of cotton or fabric samples (washed with ethanol and dried) was placed in a polypropylene tube, and $10 \mathrm{~mL}$ of acetonitrile was added. The mixture was degassed with $\mathrm{N}_{2}$ for $30 \mathrm{~min}$. Then, the mixture was sonicated $(26 \mathrm{kHz}$, power $150 \mathrm{~W}$, amplitude $100 \%)$ for $30 \mathrm{~min}$ in an ice-water bath. After sonication, the samples were dried under $\mathrm{N}_{2}$, and then the ESR measurement was recorded immediately.

Determination of the Radical Numbers. Fifty up to $500 \mathrm{mg}$ of cellulose samples (cotton, cotton fabric, viscose, or tencel, washed with ethanol and dried) were placed in a polypropylene tube, and 10 $\mathrm{mL}$ of acetonitrile was added. The mixture was sonicated $(26 \mathrm{kHz}$, power $150 \mathrm{~W}$, amplitude $100 \%$ ) for 30 to $60 \mathrm{~min}$ in an ice-water bath. After sonication, cellulose samples were immediately placed in DPPH solution $(0.039 \mathrm{mM}, 10 \mathrm{~mL}$, in acetonitrile) and stored in the dark. After the indicated waiting time, $2 \mathrm{~mL}$ of supernatant containing the DPPH solution was diluted to $4 \mathrm{~mL}$ with acetonitrile. This solution was subjected to UV-vis spectroscopy for the determination of the remaining DPPH and calculation of the produced mechanoradicals. Cellulose samples were washed with acetonitrile and dried in a vacuum before SEM, FTIR-ATR, and XRD analysis.
Preparation of the Fabric-Metal Nanocomposites. Fifty milligrams of cellulose samples (cotton, cotton fabric, viscose or tencel) and $6 \mathrm{~mL}$ of metal ion solution $\left(2.5 \mathrm{mM}, \mathrm{HAuCl}_{4}, \mathrm{AgNO}_{3}\right.$ in $\mathrm{H}_{2} \mathrm{O}$ ) were sonicated $(26 \mathrm{kHz}$, power $150 \mathrm{~W}$, amplitude $100 \%)$ for $30 \mathrm{~min}$ in an ice-water bath. Obtained nanocomposites were washed with $\mathrm{H}_{2} \mathrm{O}$ and dried in a vacuum.

Color of the Fabric-Metal Nanocomposites. Photographs of fabrics (before and after nanoparticles formation) were taken under identical light conditions. Then, the images were processed with ImageJ software by splitting the image into three red, green, and blue channels (scale 0-255). The resulting color values were fitted into the RGB wheel showing fabric color changes.

Reduction of 4-Nitrophenol. To a solution of 4-NPh in $\mathrm{H}_{2} \mathrm{O}(0.30$ $\mathrm{mM}, 3 \mathrm{~mL})$, a solution of $\mathrm{NaBH}_{4}$ in $\mathrm{H}_{2} \mathrm{O}(0.70 \mathrm{M}, 0.375 \mathrm{~mL})$ was added. Then, $10 \mathrm{mg}$ of cotton-Au NPs (total Au content: $33.4 \mu \mathrm{g}$ in cotton- $\mathrm{Au}$ nanocomposite and $16 \mu \mathrm{g}$ in cotton fabric-Au nanocomposite) was added as a catalyst. The reaction was conducted in a quartz cuvette at room temperature and monitored using UV-vis spectroscopy.

Antimicrobial Activity of Fabric-Ag Nanocomposites. To assess the antimicrobial activity of cotton-, viscose-, and tencel-Ag nanocomposites, an agar disc diffusion assay was performed for each fabric. Inhibition of growth was tested on both Gram-negative (Escherichia coli) and Gram-positive (Bacillus subtilis) cultures. The overnight grown bacteria culture was diluted in Lysogeny broth (LB) at a 1:100 ratio and grown until mid log phase $($ OD600 $=0.5$, approximately). Then, bacteria cultures diluted to a cell concentration of $5 \times 106$ CFU per mL (optical density of 1 at $600 \mathrm{~nm}$ was taken 109 $\mathrm{CFU}$ and $5 \times 108 \mathrm{CFU}$ per $\mathrm{mL}$ for E. coli and B. subtilis, respectively). A total of $100 \mu \mathrm{L}$ of diluted culture was spread on an agar plate. UVsterilized and circle-shaped fabrics were placed at the center of the agar plate. The agar plates were incubated at $37^{\circ} \mathrm{C}$ overnight. Images were taken via using Vilber imaging platform. ImageJ software was used to measure cell-free zone distances from fabrics.

Laundering Durability of Fabric-Ag Nanocomposites. Fabrics $(50 \mathrm{mg})$ were washed with $50 \mathrm{~mL}$ of an aqueous solution of commercially available detergent $(2.0 \% \mathrm{w} / \mathrm{w})$ in a beaker (diameter, $50 \mathrm{~mm}$ ), stirred ( $300 \mathrm{rpm}$, magnetic stirrer, $9 \mathrm{~mm} \times 25 \mathrm{~mm}$ ) at $25{ }^{\circ} \mathrm{C}$ for $10 \mathrm{~min}$, then rinsed with deionized water $(10 \mathrm{~mL} \times 3$ times $)$ and dried under a vacuum. The process was repeated 5, 10, and 15 times.

Coating of Fabric-Ag Nanocomposites. Coating with Alginate. A thin layer of aqueous alginate solution $(1 \%, \mathrm{w} / \mathrm{w})$ was displayed on tencel-Ag nanocomposite. Then, the sample was immersed in the aqueous solution of $\mathrm{CaCl}_{2}(3 \%, \mathrm{w} / \mathrm{w})$ and placed in the oven at $50{ }^{\circ} \mathrm{C}$ overnight.

Coating with Agarose. A thin layer of aqueous agarose solution $(2 \%, \mathrm{w} / \mathrm{w})$ was displayed on the tencel-Ag nanocomposite. Then, the sample was left at room temperature for $24 \mathrm{~h}$.

Atomic Percentage (atom \%) Calculations. The atom percentage of gold in cotton-Au nanocomposites was calculated based on the peak's area evaluated from XPS survey for each nanocomposite. The following sensitivity factors were used for the calculations: 2.881 (O 1s), 1.000 (C 1s), and 20.735 (Au 4f). The atomic percentage is an average of at least five independent XPS measurements.

Calculation of the Crystallinity Index from XRD Measurements. Crystallinity $(C)$ was determined by the peak height method developed by Segal et al., ${ }^{89}$ calculated by the following equation:

$$
C=100 \times \frac{I_{200}-I_{\mathrm{am}}}{I_{200}}[\%]
$$

where $I_{200}$ is the maximum intensity of the 200 lattice plane and $I_{\mathrm{am}}$ is the intensity of amorphous or noncrystalline portions in cellulose.

\section{CONCLUSIONS}

In this work, the formation of cotton- and fabric-metal nanocomposites was achieved via ultrasonication of cotton and fabrics. The ultrasonication, which produces mechanoradicals that reduce the aqueous metal ions, did not cause significant 
structural changes in cotton and fabric samples. The one-step access to cotton- and fabric-metal nanocomposites also eliminates conventionally used hazardous solvents and reducing and stabilizing agents. In this study, we displayed the formation of fabric composites with Ag NPs that are toxic to both Gram-positive and Gram-negative bacteria, and the formation of $\mathrm{Au} \mathrm{NP}$-fabric composites, which are catalytically active. We believe our green and straightforward method can be used to obtain other functional textiles and materials that can be used in, e.g., medical materials, energy applications, or wastewater treatment.

\section{ASSOCIATED CONTENT}

\section{SI Supporting Information}

The Supporting Information is available free of charge at https://pubs.acs.org/doi/10.1021/acssuschemeng.0c05493.

ESR spectra of fabrics; SEM images, XRD, ATR-FTIR of sonicated cotton, and fabrics; SEM and TEM images, XRD, XPS, RGB analysis reflectance spectra of cottonand fabric-based nanocomposites; Young's modulus of cotton fabric and cotton fabric-Ag nanocomposite; the proposed mechanism of metal ion reduction to metal $\mathrm{NPs}$; the reduction of $4-\mathrm{NPh}$ to $4-\mathrm{APh}$ in the presence of cotton-based nanocomposites; the antimicrobial action of agarose- and alginate-coated Tencel-Ag nanocomposites; the number of radicals per gram of cotton/fabric formed by sonication; percent crystallinities of cotton and fabrics after sonication; kinetic parameters for the 4-nitrophenol reduction; the metal content in $50 \mathrm{mg}$ of nanocomposites (PDF)

\section{AUTHOR INFORMATION}

Corresponding Author

Bilge Baytekin - Department of Chemistry and National Nanotechnology Institute (UNAM), Bilkent University, 06800 Ankara, Turkey; (i) orcid.org/0000-0002-38673863; Email: b-baytekin@fen.bilkent.edu.tr

\section{Authors}

Joanna Kwiczak-Yiğitbaşı - Department of Chemistry, Bilkent University, 06800 Ankara, Turkey; (ㅇ orcid.org/ 0000-0002-0704-9056

Mine Demir - Department of Chemistry, Bilkent University, 06800 Ankara, Turkey; 이이이.org/0000-0003-1331-0983

Recep Erdem Ahan - National Nanotechnology Institute (UNAM), Bilkent University, 06800 Ankara, Turkey; (1) orcid.org/0000-0002-6061-9062

Sedat Canlı - Central Laboratory, Middle East Technical University, 06800 Ankara, Turkey

Urartu Özgür Şafak Şeker - National Nanotechnology Institute (UNAM), Bilkent University, 06800 Ankara, Turkey; (1) orcid.org/0000-0002-5272-1876

Complete contact information is available at: https://pubs.acs.org/10.1021/acssuschemeng.0c05493

\section{Author Contributions}

"J.K-.Y. and M.D. contributed equally. B.B. conceived the project idea, supervised and coordinated the work. J.K-.Y. and M.D. carried out the experiments. J.K-.Y and S.C. carried out ESR measurements. R.E.A. carried out the antimicrobial tests under the supervision of U.Ş. J.K-.Y. and B.B. wrote the manuscript. All authors have approved the final version of the manuscript.

Notes

The authors declare no competing financial interest.

\section{ACKNOWLEDGMENTS}

This work was supported by the Scientific and Technological Research Council of Turkey (TÜBITAK) under project number 115Z452. We thank Middle East Technical University Central Laboratory and Prof. Dr. Burcu Akata Kurç for the work collaboration on ESR measurements. We also thank Dr. Dirk Simroth (Hielscher Ultrasonics) for his help in ultrasonics, Mustafa Güler for TEM analysis, Esra Arman for mechanical tests, and Mr. Murat Demir for valuable discussions on cotton fabrics.

\section{REFERENCES}

(1) Klemm, D.; Heublein, B.; Fink, H.-P.; Bohn, A. Cellulose: Fascinating Biopolymer and Sustainable Raw Material. Angew. Chem., Int. Ed. 2005, 44 (22), 3358-3393.

(2) Kalia, S.; Dufresne, A.; Cherian, B. M.; Kaith, B. S.; Avérous, L.; Njuguna, J.; Nassiopoulos, E. Cellulose-Based Bio- and Nanocomposites: A Review. Int. J. Polym. Sci. 2011, 2011, 1-35.

(3) Kaushik, M.; Moores, A. Review: Nanocelluloses as Versatile Supports for Metal Nanoparticles and Their Applications in Catalysis. Green Chem. 2016, 18 (3), 622-637.

(4) Murthy, S. K. Nanoparticles in Modern Medicine: State of the Art and Future Challenges. Int. J. Nanomedicine 2007, 2 (2), 129141.

(5) Santos, C. S. C.; Gabriel, B.; Blanchy, M.; Menes, O.; García, D.; Blanco, M.; Arconada, N.; Neto, V. Industrial Applications of Nanoparticles - A Prospective Overview. Mater. Today Proc. 2015, 2 (1), 456-465.

(6) Lam, E.; Hrapovic, S.; Majid, E.; Chong, J. H.; Luong, J. H. T. Catalysis Using Gold Nanoparticles Decorated on Nanocrystalline Cellulose. Nanoscale 2012, 4 (3), 997-1002.

(7) Koga, H.; Tokunaga, E.; Hidaka, M.; Umemura, Y.; Saito, T.; Isogai, A.; Kitaoka, T. Topochemical Synthesis and Catalysis of Metal Nanoparticles Exposed on Crystalline Cellulose Nanofibers. Chem. Commun. 2010, 46 (45), 8567-8569.

(8) Wu, X.; Lu, C.; Zhou, Z.; Yuan, G.; Xiong, R.; Zhang, X. Green Synthesis and Formation Mechanism of Cellulose NanocrystalSupported Gold Nanoparticles with Enhanced Catalytic Performance. Environ. Sci.: Nano 2014, 1 (1), 71-79.

(9) Kwiczak-Yigitbas1, J.; Lacin, O.; Demir, M.; Ahan, R. E.; Seker, U. O. S.; Baytekin, B. A Sustainable Preparation of Catalytically Active and Antibacterial Cellulose Metal Nanocomposites via Ball-Milling of Cellulose. Green Chem. 2020, 22, 455-464.

(10) Dev, V. R. G.; Venugopal, J.; Sudha, S.; Deepika, G.; Ramakrishna, S. Dyeing and Antimicrobial Characteristics of Chitosan Treated Wool Fabrics with Henna Dye. Carbohydr. Polym. 2009, 75 (4), 646-650.

(11) El-Shishtawy, R. M.; Asiri, A. M.; Abdelwahed, N. A. M.; AlOtaibi, M. M. In Situ Production of Silver Nanoparticle on Cotton Fabric and Its Antimicrobial Evaluation. Cellulose 2011, 18 (1), 7582.

(12) Ilić, V.; šaponjić, Z.; Vodnik, V.; Potkonjak, B.; Jovančić, P.; Nedeljković, J.; Radetić, M. The Influence of Silver Content on Antimicrobial Activity and Color of Cotton Fabrics Functionalized with Ag Nanoparticles. Carbohydr. Polym. 2009, 78 (3), 564-569.

(13) Gupta, P.; Bajpai, M.; Bajpai, S. K. Investigation of Antibacterial Properties of Silver Nanoparticle-Loaded Poly (Acrylamide-CoItaconic Acid)-Grafted Cotton Fabric. J. Cotton Sci. 2008, 12 (3), 280-286.

(14) Peng, L.; Guo, R.; Lan, J.; Jiang, S.; Wang, X. Silver Nanoparticle Coating on Cotton Fabric Modified with Poly- 
(Diallyldimethylammonium Chloride). Mater. Technol. 2016, 31 (8), 431-436.

(15) Lee, H. Y.; Park, H. K.; Lee, Y. M.; Kim, K.; Park, S. B. A Practical Procedure for Producing Silver Nanocoated Fabric and Its Antibacterial Evaluation for Biomedical Applications. Chem. Commun. 2007, 28, 2959-2961.

(16) Lee, H. J.; Yeo, S. Y.; Jeong, S. H. Antibacterial Effect of Nanosized Silver Colloidal Solution on Textile Fabrics. J. Mater. Sci. 2003, 38 (10), 2199-2204.

(17) Shateri Khalil-Abad, M.; Yazdanshenas, M. E.; Nateghi, M. R. Effect of Cationization on Adsorption of Silver Nanoparticles on Cotton Surfaces and Its Antibacterial Activity. Cellulose 2009, 16 (6), $1147-1157$.

(18) Raza, Z. A.; Bilal, U.; Noreen, U.; Munim, S. A.; Riaz, S.; Abdullah, M. U.; Abid, S. Chitosan Mediated Formation and Impregnation of Silver Nanoparticles on Viscose Fabric in Single Bath for Antibacterial Performance. Fibers Polym. 2019, 20 (7), 1360-1367.

(19) Prysiazhnyi, V.; Kramar, A.; Dojcinovic, B.; Zekic, A.; Obradovic, B. M.; Kuraica, M. M.; Kostic, M. Silver Incorporation on Viscose and Cotton Fibers after Air, Nitrogen and Oxygen DBD Plasma Pretreatment. Cellulose 2013, 20 (1), 315-325.

(20) Zheng, J.; Song, F.; Wang, X.-L.; Wang, Y.-Z. In-Situ Synthesis, Characterization and Antimicrobial Activity of Viscose Fiber Loaded with Silver Nanoparticles. Cellulose 2014, 21 (4), 3097-3105.

(21) Emam, H. E.; Ahmed, H. B. Carboxymethyl Cellulose Macromolecules as Generator of Anisotropic Nanogold for Catalytic Performance. Int. J. Biol. Macromol. 2018, 111, 999-1009.

(22) Emam, H. E.; El-Bisi, M. K. Merely Ag Nanoparticles Using Different Cellulose Fibers as Removable Reductant. Cellulose 2014, 21 (6), 4219-4230.

(23) Emam, H. E.; El-Zawahry, M. M.; Ahmed, H. B. One-Pot Fabrication of AgNPs, AuNPs and Ag-Au Nano-Alloy Using Cellulosic Solid Support for Catalytic Reduction Application. Carbohydr. Polym. 2017, 166, 1-13.

(24) Feng, J.; Hontañón, E.; Blanes, M.; Meyer, J.; Guo, X.; Santos, L.; Paltrinieri, L.; Ramlawi, N.; de Smet, L. C. P. M.; Nirschl, H.; Kruis, F. E.; Schmidt-Ott, A.; Biskos, G. Scalable and Environmentally Benign Process for Smart Textile Nanofinishing. ACS Appl. Mater. Interfaces 2016, 8 (23), 14756-14765.

(25) Emam, H. E.; Zahran, M. K.; Ahmed, H. B. Generation of Biocompatible Nanogold Using H2O2-Starch and Their Catalytic/ Antimicrobial Activities. Eur. Polym. J. 2017, 90, 354-367.

(26) Ahmed, H. B.; Emam, H. E. Synergistic Catalysis of Monometallic ( $\mathrm{Ag}, \mathrm{Au}, \mathrm{Pd})$ and Bimetallic ( $\mathrm{AgAu}, \mathrm{AuPd}$ ) versus Trimetallic (Ag-Au-Pd) Nanostructures Effloresced via Analogical Techniques. J. Mol. Liq. 2019, 287, 110975.

(27) Emam, H. E.; Ahmed, H. B. Comparative Study between Homo-Metallic \& Hetero-Metallic Nanostructures Based Agar in Catalytic Degradation of Dyes. Int. J. Biol. Macromol. 2019, 138, 450461.

(28) Ahmed, H. B.; Mikhail, M. M.; El-Sherbiny, S.; Nagy, K. S.; Emam, H. E. PH Responsive Intelligent Nano-Engineer of Nanostructures Applicable for Discoloration of Reactive Dyes. J. Colloid Interface Sci. 2020, 561, 147-161.

(29) Emam, H. E.; Saad, N. M.; Abdallah, A. E. M.; Ahmed, H. B. Acacia Gum versus Pectin in Fabrication of Catalytically Active Palladium Nanoparticles for Dye Discoloration. Int. J. Biol. Macromol. 2020, 156, 829-840.

(30) Andersen, J.; Mack, J. Mechanochemistry and Organic Synthesis: From Mystical to Practical. Green Chem. 2018, 20 (7), 1435-1443.

(31) Temnikov, M. N.; Anisimov, A. A.; Zhemchugov, P. V.; Kholodkov, D. N.; Goloveshkin, A. S.; Naumkin, A. V.; Chistovalov, S. M.; Katsoulis, D.; Muzafarov, A. M. Mechanochemistry - a New Powerful Green Approach to the Direct Synthesis of Alkoxysilanes. Green Chem. 2018, 20 (9), 1962-1969.

(32) Colacino, E.; Porcheddu, A.; Halasz, I.; Charnay, C.; Delogu, F.; Guerra, R.; Fullenwarth, J. Mechanochemistry for "No Solvent, No
Base" Preparation of Hydantoin-Based Active Pharmaceutical Ingredients: Nitrofurantoin and Dantrolene. Green Chem. 2018, 20 (13), 2973-2977.

(33) Wiggins, K. M.; Brantley, J. N.; Bielawski, C. W. Polymer Mechanochemistry: Force Enabled Transformations. ACS Macro Lett. 2012, 1 (5), 623-626.

(34) Muñoz-Batista, M. J.; Rodriguez-Padron, D.; Puente-Santiago, A. R.; Luque, R. Mechanochemistry: Toward Sustainable Design of Advanced Nanomaterials for Electrochemical Energy Storage and Catalytic Applications. ACS Sustainable Chem. Eng. 2018, 6 (8), 9530-9544.

(35) Baláž, M.; Daneu, N.; Balážová, L.; Dutková, E.; Tkáčiková, L.; Briančin, J.; Vargová, M.; Balážová, M.; Zorkovská, A.; Baláž, P. BioMechanochemical Synthesis of Silver Nanoparticles with Antibacterial Activity. Adv. Powder Technol. 2017, 28 (12), 3307-3312.

(36) Stefanovic, B.; Pirker, K. F.; Rosenau, T.; Potthast, A. Effects of Tribochemical Treatments on the Integrity of Cellulose. Carbohydr. Polym. 2014, 111, 688-699.

(37) Sakaguchi, M.; Ohura, T.; Iwata, T.; Takahashi, S.; Akai, S.; Kan, T.; Murai, H.; Fujiwara, M.; Watanabe, O.; Narita, M. Diblock Copolymer of Bacterial Cellulose and Poly(Methyl Methacrylate) Initiated by Chain-End-Type Radicals Produced by Mechanical Scission of Glycosidic Linkages of Bacterial Cellulose. Biomacromolecules 2010, 11 (11), 3059-3066.

(38) Baytekin, H. T.; Baytekin, B.; Grzybowski, B. A. Mechanoradicals Created in "Polymeric Sponges" Drive Reactions in Aqueous Media. Angew. Chem., Int. Ed. 2012, 51 (15), 3596-3600.

(39) Baytekin, H. T.; Baytekin, B.; Hermans, T. M.; Kowalczyk, B.; Grzybowski, B. A. Control of Surface Charges by Radicals as a Principle of Antistatic Polymers Protecting Electronic Circuitry. Science 2013, 341 (6152), 1368-1371.

(40) Baytekin, H. T.; Baytekin, B.; Huda, S.; Yavuz, Z.; Grzybowski, B. A. Mechanochemical Activation and Patterning of an Adhesive Surface toward Nanoparticle Deposition. J. Am. Chem. Soc. 2015, 137 (5), 1726-1729.

(41) Sakaguchi, M.; Makino, M.; Ohura, T.; Iwata, T. Mechanoanions Produced by Mechanical Fracture of Bacterial Cellulose: Ionic Nature of Glycosidic Linkage and Electrostatic Charging. J. Phys. Chem. A 2012, 116 (40), 9872-9877.

(42) Solala, I.; Henniges, U.; Pirker, K. F.; Rosenau, T.; Potthast, A.; Vuorinen, T. Mechanochemical Reactions of Cellulose and Styrene. Cellulose 2015, 22 (5), 3217-3224.

(43) Ohura, T.; Tsutaki, Y.; Sakaguchi, M. Novel Synthesis of Cellulose-Based Diblock Copolymer of Poly(Hydroxyethyl Methacrylate) by Mechanochemical Reaction. Sci. World J. 2014, 2014, 127506.

(44) Gedanken, A. Using Sonochemistry for the Fabrication of Nanomaterials. Ultrason. Sonochem. 2004, 11 (2), 47-55.

(45) Pankaj, S.; Ashokkumar, M. Theoretical and Experimental Sonochemistry Involving Inorganic Systems; Springer: Dordrecht, 2011.

(46) Sáez, V.; Mason, T. J. Sonoelectrochemical Synthesis of Nanoparticles. Molecules 2009, 14 (10), 4284-4299.

(47) Xu, H.; Zeiger, B. W.; Suslick, K. S. Sonochemical Synthesis of Nanomaterials. Chem. Soc. Rev. 2013, 42 (7), 2555-2567.

(48) Kumar, B.; Smita, K.; Cumbal, L.; Debut, A.; Pathak, R. N. Sonochemical Synthesis of Silver Nanoparticles Using Starch: A Comparison. Bioinorg. Chem. Appl. 2014, 2014, 1-8.

(49) Karunakaran, C.; Rajeswari, V.; Gomathisankar, P. Antibacterial and Photocatalytic Activities of Sonochemically Prepared $\mathrm{ZnO}$ and Ag-ZnO. J. Alloys Compd. 2010, 508 (2), 587-591.

(50) Kan, C.; Cai, W.; Li, C.; Zhang, L.; Hofmeister, H. Ultrasonic Synthesis and Optical Properties of Au/Pd Bimetallic Nanoparticles in Ethylene Glycol. J. Phys. D: Appl. Phys. 2003, 36 (13), 1609-1614.

(51) Qiu, X.-F.; Zhu, J.-J.; Chen, H.-Y. Controllable Synthesis of Nanocrystalline Gold Assembled Whiskery Structures via Sonochemical Route. J. Cryst. Growth 2003, 257 (3), 378-383.

(52) Okitsu, K.; Yue, A.; Tanabe, S.; Matsumoto, H.; Yobiko, Y. Formation of Colloidal Gold Nanoparticles in an Ultrasonic Field: 
Control of Rate of Gold(III) Reduction and Size of Formed Gold Particles. Langmuir 2001, 17 (25), 7717-7720.

(53) Damm, C.; Peukert, W. Mechano-Chemical Radical Formation and Polymerization Initiation during Wet Grinding of Alumina. J. Colloid Interface Sci. 2011, 363 (1), 386-392.

(54) Delogu, F. Mechanochemical Behavior of Surface Radicals in Ground Quartz. J. Phys. Chem. C 2011, 115 (43), 21230-21235.

(55) Laçin, Ö.; Kwiczak-Yiǧitbaşı, J.; Erkan, M.; Cevher, Ş. C.; Baytekin, B. The Morphological Changes upon Cryomilling of Cellulose and Concurrent Generation of Mechanoradicals. Polym. Degrad. Stab. 2019, 168, 108945.

(56) Solala, I.; Volperts, A.; Andersone, A.; Dizhbite, T.; MironovaUlmane, N.; Vehniainen, A.; Pere, J.; Vuorinen, T. Mechanoradical Formation and Its Effects on Birch Kraft Pulp during the Preparation of Nanofibrillated Cellulose with Masuko Refining. Holzforschung 2012, 66, 477-483.

(57) Hon, D. N.-S. Formation and Behavior of Mechanoradicals in Pulp Cellulose. J. Appl. Polym. Sci. 1979, 23 (5), 1487-1499.

(58) Stefanovic, B.; Rosenau, T.; Potthast, A. Effect of Sonochemical Treatments on the Integrity and Oxidation State of Cellulose. Carbohydr. Polym. 2013, 92 (1), 921-927.

(59) Thygesen, A.; Oddershede, J.; Lilholt, H.; Thomsen, A. B.; Ståhl, K. On the Determination of Crystallinity and Cellulose Content in Plant Fibres. Cellulose 2005, 12 (6), 563.

(60) Zhang, L.; Ruan, D.; Zhou, J. Structure and Properties of Regenerated Cellulose Films Prepared from Cotton Linters in $\mathrm{NaOH} /$ Urea Aqueous Solution. Ind. Eng. Chem. Res. 2001, 40 (25), $5923-5928$

(61) Xu, Y.; Lu, Z.; Tang, R. Structure and Thermal Properties of Bamboo Viscose, Tencel and Conventional Viscose Fiber. J. Therm. Anal. Calorim. 2007, 89 (1), 197-201.

(62) Marchessault, R. H.; Liang, C. Y. Infrared Spectra of Crystalline Polysaccharides. III. Mercerized Cellulose. J. Polym. Sci. 1960, 43 (141), 71-84.

(63) Kalutskaya, E. P.; Gusev, S. S. An Infrared Spectroscopic Investigation of the Hydration of Cellulose. Polym. Sci. U.S.S.R. 1980, 22 (3), 550-556.

(64) Pinto, R. J. B.; Neves, M. C.; Pascoal, C.; Trindade, T. Composites of Cellulose and Metal Nanoparticles. Nanocomposites New Trends Dev.; InTech, 2012; DOI: 10.5772/50553.

(65) Thouti, E.; Chander, N.; Dutta, V.; Komarala, V. K. Optical Properties of Ag Nanoparticle Layers Deposited on Silicon Substrates. J. Opt. 2013, 15 (3), 035005.

(66) Huang, K.; Pan, W.; Zhu, J. F.; Li, J. C.; Gao, N.; Liu, C.; Ji, L.; Yu, E. T.; Kang, J. Y. Asymmetric Light Reflectance from Metal Nanoparticle Arrays on Dielectric Surfaces. Sci. Rep. 2015, 5 (1), 18331.

(67) Shi, X.; Mao, Y.; Daniel, L. N.; Saffiotti, U.; Dalal, N. S.; Vallyathan, V. Silica Radical-Induced DNA Damage and Lipid Peroxidation. Environ. Health Perspect. 1994, 102 (10), 149-154.

(68) Shahidi, F.; Zhong, Y. Lipid Oxidation and Improving the Oxidative Stability. Chem. Soc. Rev. 2010, 39 (11), 4067-4079.

(69) Penava, Z.; Simic Penava, D.; Knezic, Z. Determination of the Elastic Constants of Plain Woven Fabrics by a Tensile Test in Various Direction. Fibers Text. East. Eur. 2014, 22 (104), 57-63.

(70) Sawhney, A. P. S.; Condon, B.; Singh, K. V.; Pang, S. S.; Li, G.; Hui, D. Modern Applications of Nanotechnology in Textiles. Text. Res. J. 2008, 78 (8), 731-739.

(71) Xu, Q.; Xie, L.; Diao, H.; Li, F.; Zhang, Y.; Fu, F.; Liu, X. Antibacterial Cotton Fabric with Enhanced Durability Prepared Using Silver Nanoparticles and Carboxymethyl Chitosan. Carbohydr. Polym. 2017, 177, 187-193.

(72) Fountoulaki, S.; Daikopoulou, V.; Gkizis, P. L.; Tamiolakis, I.; Armatas, G. S.; Lykakis, I. N. Mechanistic Studies of the Reduction of Nitroarenes by $\mathrm{NaBH} 4$ or Hydrosilanes Catalyzed by Supported Gold Nanoparticles. ACS Catal. 2014, 4 (10), 3504-3511.

(73) Emam, H. E.; Mikhail, M. M.; El-Sherbiny, S.; Nagy, K. S.; Ahmed, H. B. Metal-Dependent Nano-Catalysis in Reduction of
Aromatic Pollutants. Environ. Sci. Pollut. Res. 2020, 27 (6), 64596475.

(74) Emam, H. E.; Attia, M. A.; El-Dars, F. M. S. E.; Ahmed, H. B. Emerging Use of Homogenic and Heterogenic Nano-Colloids Synthesized via Size-Controllable Technique in Catalytic Potency. J. Polym. Environ. 2020, 28 (2), 553-565.

(75) Tang, J.; Shi, Z.; Berry, R. M.; Tam, K. C. Mussel-Inspired Green Metallization of Silver Nanoparticles on Cellulose Nanocrystals and Their Enhanced Catalytic Reduction of 4-Nitrophenol in the Presence of $\beta$-Cyclodextrin. Ind. Eng. Chem. Res. 2015, 54 (13), 3299-3308.

(76) Yuan, H.; Chen, L.; Hong, F. F. A Biodegradable Antibacterial Nanocomposite Based on Oxidized Bacterial Nanocellulose for Rapid Hemostasis and Wound Healing. ACS Appl. Mater. Interfaces 2020, 12 (3), 3382-3392.

(77) Rodrigues, A. G.; Romano de Oliveira Gonçalves, P. J.; Ottoni, C. A.; de Cássia Ruiz, R.; Morgano, M. A.; de Araújo, W. L.; de Melo, I. S.; De Souza, A. O. Functional Textiles Impregnated with Biogenic Silver Nanoparticles from Bionectria Ochroleuca and Its Antimicrobial Activity. Biomed. Microdevices 2019, 21 (3), 56.

(78) Chen, W.; Chen, J.; Li, L.; Wang, X.; Wei, Q.; Ghiladi, R. A.; Wang, Q. Wool/Acrylic Blended Fabrics as Next-Generation Photodynamic Antimicrobial Materials. ACS Appl. Mater. Interfaces 2019, 11 (33), 29557-29568.

(79) O’Hanlon, S. J.; Enright, M. C. A Novel Bactericidal Fabric Coating with Potent in Vitro Activity against Meticillin-Resistant Staphylococcus Aureus (MRSA). Int. J. Antimicrob. Agents 2009, 33 (5), 427-431.

(80) Dastjerdi, R.; Montazer, M. A Review on the Application of Inorganic Nano-Structured Materials in the Modification of Textiles: Focus on Anti-Microbial Properties. Colloids Surf., B 2010, 79 (1), 518.

(81) Ahmed, H. B.; Emam, H. E.; Mashaly, H. M.; Rehan, M. Nanosilver Leverage on Reactive Dyeing of Cellulose Fibers: Color Shading, Color Fastness and Biocidal Potentials. Carbohydr. Polym. 2018, 186, 310-320.

(82) Emam, H. E.; Rehan, M.; Mashaly, H. M.; Ahmed, H. B. Large Scaled Strategy for Natural/Synthetic Fabrics Functionalization via Immediate Assembly of AgNPs. Dyes Pigm. 2016, 133, 173-183.

(83) Dastjerdi, R.; Montazer, M.; Shahsavan, S. A New Method to Stabilize Nanoparticles on Textile Surfaces. Colloids Surf., A 2009, 345 (1), 202-210.

(84) Franci, G.; Falanga, A.; Galdiero, S.; Palomba, L.; Rai, M.; Morelli, G.; Galdiero, M. Silver Nanoparticles as Potential Antibacterial Agents. Molecules 2015, 20 (5), 8856-8874.

(85) Zahran, M. K.; Ahmed, H. B.; El-Rafie, M. H. Surface Modification of Cotton Fabrics for Antibacterial Application by Coating with AgNPs-Alginate Composite. Carbohydr. Polym. 2014, $108,145-152$.

(86) Li, J.; He, J.; Huang, Y. Role of Alginate in Antibacterial Finishing of Textiles. Int. J. Biol. Macromol. 2017, 94, 466-473.

(87) Pan, H.; Wang, W.; Pan, Y.; Song, L.; Hu, Y.; Liew, K. M. Formation of Self-Extinguishing Flame Retardant Biobased Coating on Cotton Fabrics via Layer-by-Layer Assembly of Chitin Derivatives. Carbohydr. Polym. 2015, 115, 516-524.

(88) Bajpai, S. K.; Bajpai, M.; Sharma, L. Copper Nanoparticles Loaded Alginate-Impregnated Cotton Fabric with Antibacterial Properties. J. Appl. Polym. Sci. 2012, 126, 319-326.

(89) Segal, L.; Creely, J. J.; Martin, A. E.; Conrad, C. M. An Empirical Method for Estimating the Degree of Crystallinity of Native Cellulose Using the X-Ray Diffractometer. Text. Res. J. 1959, 29 (10), 786-794. 